\title{
The New Trend and Application of Customer Relationship Management under Big Data Background
}

\author{
Lan Wang \\ School of Business, Beijing Language and Culture University, Beijing, China \\ Email:im2003@163.com
}

Received 12 June 2016; accepted 23 July 2016; published 26 July 2016

Copyright @ 2016 by author and Scientific Research Publishing Inc.

This work is licensed under the Creative Commons Attribution International License (CC BY).

http://creativecommons.org/licenses/by/4.0/

(c) (i) Open Access

\begin{abstract}
One of the important trends of marketing management is digitization. The concept of digitization has been imported to many fields and is well known to everyone. However, because of the limitation of digitization's meaning and expansion, companies have different understandings of it. The meaning of the digital CRM is a digital customer experience that is specially built and customer-oriented. It is a business reform that improves value creation. Current companies not only focus on the effects brought by technologies, but also focus on how the digital business mode makes profits. This article explains the evolution of marketing management from traditional CRM to analytical CRM to digital CRM. Based on the characteristics of digital CRM, we discussed the new trend and application of CRM.
\end{abstract}

\section{Keywords}

\section{Customer Relationship Management, Big Data, Data Integration}

\section{Introduction}

The traditional CRM is a competition that defines products as the center and is driven by sales staff. It recognized clients by statistics captured by tools and applications, paid attention to sales automation as well as customer care and support, and regarded customer relationship as business. However, the modern CRM focuses on the position and differentiation centered on customers. It reaches better predictions by customer insights, and realizes or even surpasses expectations of customers. The company integrates the market, selling and service fields on the basis of customer experience, evaluates the entire customer experience, as well as balancing the value of customer relationship. 
The modern CRM defines a fresh management theory of “customer orientation”. Firstly, by text analysis of big data from social media, the company can discover customer motivation and reduce income loss, and these are called "customers who know you”. Secondly, the company needs to launch new products and channels constantly, and to stay in touch with clients frequently, and these are called "customers who touch you". Lastly, by developing individualized products, combining multiple channels, and expanding client contacts to satisfy the needs of the client, the company can "win the customer”. Eventually, the company can establish the organization and management that are customer-oriented, and can improve its internal management pattern.

The early CRM focused on "analysis” and “operation”. The operational CRM mainly collected information, while the analytical CRM effectively integrated the collected information to support decision makers. By collecting a great amount of client information, market information and service information, the operational CRM enhanced the integration of sales, marketing and services, the streaming and automation of all business process, including the integration of clients' "contacting point” from multiple channels, as well as the smooth connection of the foreground and background operation. The analytical CRM mainly acquired data from the original system of the operational CRM. It integrated the data of sales, services, marketing and business operations. By using data warehouse, data mining and decision supporting technology, the analytical CRM transferred data into useful information, offering more precise guidance to client services and new product development [1].

\section{The Development Trend of CRM}

One of the important trends of today's world is digitization. Digitization has permeated various fields of human's work and life, such as online trading, social networking and the Internet of Things. In China, the forming and development of this trend is more attractive. It can be predicted that, in future years, almost all the customers in China will possess smart mobile devices and can get access to the Internet at any time. Customers can learn about products more easily than before because of the digital lifestyle, and they can share comments, as well as showing their tastes via online purchasing.

The concept of digitization has been imported to many fields and is well known to everyone. However, because of the limitation of digitization's meaning and expansion, companies have different understandings of it. Many of the understandings of digitization are about digital technologies and hardware, such as the cloud technology, big data and mobile devices, but these are not enough.

\subsection{Digital CRM}

The meaning of the digital CRM is a digital customer experience that is specially built and customer-oriented. It is a business reform that improves value creation methods. By innovatively combine and integrate business information, resources and digital technologies, companies can establish unique customer experiences and acquire innovative results that can realize new international digitization expectations to realize income increases. Compared with the former situation, current companies not only focus on the effects brought by technologies, but also focus on how the digital business mode makes profits [2].

As content providers, music companies work with Amazon, Apple iTunes and other internet platforms to form a win-win mode. Once digital music stores sell music products, the profits are shared. By statistics analysis, internet platforms recommend music to customers according to their tastes to improve sales. The music industry realizes its transformation and upgrading by developing the digital business mode "music as services" to provide individualized music experiences for clients. Take music industry as an example: music companies earn profits by publishing and selling cassettes in traditional business. Then, digital music products were developed, and the era of digital products came. In this period of time, the biggest challenge the music industry faces was that the digital products had no copyrights, which significantly affected the income of music companies. Nevertheless, the digital business mode reformed the music industry and realized the way where music companies make profits from copyrights.

Every company must turn into a digitized company, especially the digitization in the CRM field. In the world of digitization, the future of companies depends on two factors: why managers adopt digital technologies, and how digital technologies change companies' business mode. The goal of enhancements requires companies to become digitized, and this process is entirely different from the way of substituting old technologies with new technologies without operational mode alternations. Some management teams thought that their companies have been digitized, but their companies are significantly lower than the digitization standards. When its business 
process realizes simple digitization, the company only learns how to use the technology, but does not change its business mode [3]. For example, the efficiency may be increased by applying new technologies to current process, but the prospect of the company may not be improved. Moreover, installing mobile customer applications can increase sales, but cannot increase the company's income, meaning that the digitization strategy is not thoroughly utilized. In such situations, new methods are used, but customer behaviors are not changed, because the company does not offer motivation for the expansion of customer relationship.

\subsection{The Characteristics of Digital CRM}

The behavior of Chinese customers grows more digitized. So far, almost $40 \%$ of urban customers purchase online once a week or more. According to the survey “will you expand your purchasing channels in the future?”, Chinese customers plan to increase online shopping, surpassing their peers in the USA by 20\%, and Chinese customers are more willing to conduct mobile shopping. It can be seen that the digitized customers in China are more aggressive than those in other countries, and that Chinese customers are positively adopting digitized lifestyles. Although most Chinese customers have accepted and have got closer to digital purchasing, it is hard for companies to keep those digitized customers. Digitized customers are more flexible, and they change their purchasing behaviors anytime. Facing to the complicated and changing Chinese customers, companies can never adopt only one strategy to obtain market shares like they used to do. Therefore, companies need Digital CRM solutions to compete for digitized purchasing.

The transition of Digital that is customer-oriented contains three core elements: delight your clients, reestablish business mode and a flexible platform. This is to say that even the maturity of these three elements in a company is not at the same level, the transition could only happen when the three elements are executed together [4].

1) Delighting your clients

Companies have to understand their clients more deeply, as well as providing seamless and differentiated experiences and services for them. Additionally, companies need more related and simple methods to make their clients happy.

Customer insights

Compared to the past, the digital era makes companies understand their clients more and suggest customer insights. In previous times, companies only knew who their clients were, their basic profiles such as names and phone numbers, the value their clients could bring, and the products clients would pay for. Companies had no idea about purchasing behaviors and motivation of their clients. The digital era largely enriched client profiles and added behaviors and motivation. By using digital technologies, companies can clearly get to know clients’ preferences in purchasing, favorite channels and modes of payments. More importantly, companies can discern if it is the price, promotion or comments that motivate clients’ purchasing [5].

2) The change of customer behaviors

The digital technology pushes reforms from the inside to the outside. Technologies such as mobile technologies, data analysis, social media and cloud platforms basically concentrate on customers as well as providing various information and connections to change the meaning of every "Moment of Truth". The growth in business is no longer a process that promotes new products and motivates customer purchasing through linear purchases. Currently, even the most careless business observer can find out that previous customers conducted linear purchases, which is called “A Funnel Mode”. The Funnel Mode starts from customers' focus on products and services, and ends at the establishment of their purchasing and loyalty. In nowadays, the mobile Internet, social media and online retailers significantly influence customers' purchasing process, and the way customers communicate with sellers and buy products become diverse. As long as today's customers have smart phones, tablet computers or personal computers, they can log on to any part of the online purchasing process at anytime and anywhere. Meanwhile, no matter online or offline, customers can transfer among channels and processes without limitation. Various former selling channels are disappearing, and a mode that unites all elements is growing [6].

In the traditional sales funnel, customers purchase in a linear path, so sellers have rather strong controls in the process. Accenture's non-stop shopping experience model demonstrates the influence digitization has in purchasing: the interactions between clients and sellers as well as purchasing channels are changing. Meanwhile, purchasing processes are dynamic, impressionable and constant. Making comments is already the key in pur- 
chasing, and purchasing channels are always prepared for customers to use.

The current purchasing process is more dynamic: customers can control and change their purchasing paths through technology improvements to satisfy their needs. Although today's purchasing processes are almost the same, they are different from the traditional "funnel" style. These new paths could be linear, but most of them are non-linear, such as annular and zigzag styles.

The current purchasing process is easier to be obtained: customers' options are a great deal more various than before, and any company cannot completely control them. Moreover, the influence from the third party is increasing, and the range it affects is expanding. Customers have multiple choices in every field, and they can buy products whenever and wherever. Therefore, every company could be an alternative or a provider. Meanwhile, in a more open environment, clients suggest requirements of higher transparency when their profiles are used by companies. Even when companies make use of customers' profiles to improve the business level, transparency requirements from clients must be met.

The purchasing process is more persistent: digital technology, mobile technology and social technology have made the "time-difference shopping" no longer exist. Online shopping does not have time limits, and products can be sold with only a few clicks of fingertips. It is to say that customers are almost following shopping information in channels all the time [7].

3) Rebuilding the business mode

Companies need to reform its brand management and operational mode to a customer-oriented and agile style. Companies should integrate analytical methods to their core culture, and their business systems should be more effective and agile with a better ROI.

In the "moment of truth" of a client's life circle, by combining digitization technologies with business, a company should execute more agile marketing, provide differentiated customer experience, and improve customer loyalty to acquire income. For example, by using digital location technology, Starbucks Coffee can promote its new products and marketing campaigns to customers who are physically close to its stores. Promotions at the right time can stimulate customers' interests, and thus increase the passenger flow and sales amount [8].

4) Flexible technology platform

In order to better sales, contents and business technology frame, as well as improving customer experience and business effectiveness, the technology system should be stronger, obtain high scalability and can be executed shortly. Digital business highly concentrates on clients. Based on data management and driven by data analysis, digital business should suggest client insights, design contents, choose appropriate channels, provide individualized interactions, and improve customer experiences.

Companies need to quickly improve their digitization capability and build digitization technology platforms with the help of the latest digitization technology. For example, companies can establish seamless purchasing experiences at the front desk, form digitization capability in the background services, integrate and connect different types of data stream, conduct smart data analysis, and establish individualized services and event-driven marketing. At the time a customer touches the channel, the company can offer suitable products to them according to his/her situation [9].

\section{Big Data and CRM Model}

\subsection{The CRM Application in Big Data}

Compared to former data mining, the big data focuses on finding problems from data and emphasizes on business analysis, but not the previous situation where data was found when problems existed and where the business application was the core. The function of data mining can cover client management, marketing, sales executive and after-sales services. Specific application situations are not the same for different industries and companies. In below, three situations are introduced: marketing based on the full view of customers, transaction risk analysis, and equipment service enhancing through preventive maintenance.

Marketing based on the full view of customers: a customer view includes basic customer data, transaction data, interaction data, and social media data. The full view can generate social media's public opinion analysis, better precision promotion, customer division, customer profit analysis, multi channel interaction analysis, loyalty analysis, and customer consumption trend mining.

Marketing risk prevention: based on the integrated customer full view, a company should define risk rules and models, as well as discovering and analyzing the risk in growing scale and speed, customer trust risk and loss 
risk in time. In this way, the company can develop deeper evaluation and solutions to reduce the potential risk in its sales area.

Equipment service enhancing through preventive maintenance: after the equipment is sold, there are two ways to help customers to improve its utilization. On the one hand, by the analysis of a great amount of operational data, one can find out the best maintenance period and improve the maintenance plan of shutting down the machine to reduce breakdowns caused by overloaded. On the other hand, the company should establish non-effective models based on history data and install sensor to monitor key equipment's operation. When the condition reaches to set strategies, the equipment can take actions to reduce breakdowns.

According to Accenture's CRM project, the typical application of big data in process is as follows: firstly, from the point of function, the marketing of client full view is used as an entry point, it is because that the management of the client full view is the basis of other applications from the functions' dependent relationship. Secondly, from the point of different types of data, structured data analysis is usually used in the primary period according to the level of demanding and preparation of external data, and then the data develops to an unstructured way. Lastly, companies need to examine the situation for those applications that need business premises. For example, the application of the innovative after sales services needs to be examined for its business premises, because the realization of this function needs the cooperation of the provider and the purchaser, including the installment of sensors, network building of return data-the establishment of the basis of the Internet of Things.

\subsection{The Application of Mobile CRM}

We can conclude that the higher the value is, the more complex the mobility is, so mobility needs a greater reform in sales and services. Mobility is the main concentration of CSOs in the field of CRM. The reasons are as follows: firstly, salesmen can use less resource to complete more business, and they can use key information obtained by simple methods to improve their selling and marketing abilities. Secondly, when confronted with customers, salesmen's creativity increases largely. For B2B clients, salesmen can understand the industry better, reveal its business values, and provide cross channel suggestions; for B2C client, salesmen can offer cross channel advice and reach to trades; for companies' CIO, they can use latest technologies to keep their companies' competence [10].

The wider utilization of mobile CRM brings bigger challenges to data safety, so fields of identity safety, statistics safety and Internet safety should be focused. For example, the safety risk can be reduced by user identity recognition, multi layer data encryption, transmittal encryption and Internet security technology.

The mobile application embodies in the mobility of CRM application, as well as external interaction and marketing:

Typical situation 1: the application used when salesmen visit clients. Specific functions include making appointments, visit preparation, automatic visit recording, information management after the visit and cue management. These functions largely promote sales and customer experiences.

Typical situation 2: B2B clients can finish the follow up of their orders' progress such as the stock status, shipped quantity, the delivery status, receipt and payment status via mobile ends.

External interaction and marketing: mainly for external clients, and the main situations include the following two:

Client interaction and services: in the future, client interactions including marker research, promotion publish, and online customer services can be accomplished by mobile applications.

The typical promotion method of mobile applications when CRM is executed: firstly is to execute the mobile solution of the chosen CRM product, and to realize the CRM mobility described above, because every CRM supports the mobile use of software. Secondly, considering users' acceptability, companies use widely accepted platforms such as We chat to interact with customers. Companies can define basic functions on these platforms, such as promotions, location searches and customer profile bindings.

\subsection{The Application of the Cloud Calculation in CRM}

The application of the cloud calculation in the management of client relationship embodies in four aspects:

Firstly, IaaS. A company builds the CRM system, and the hardware environment is settled in the cloud. The cloud can support the needed server, storage, Internet, water/electricity/venue to assist the establishment of the CRM system. The cloud here can be recognized as a public cloud or a private cloud. One example of the public 
cloud is to rent Amazon's cloud service, and an example of the private cloud is a cloud built in the company. Small and medium enterprises usually choose the former type, while large enterprises pick the latter type more. It is to say that the demanding process and time costs in the CRM executive process no longer exist, and a usable machine is obtained from the Internet. For users, the "virtual machine" serves for a part of the group or is used as an independent server. In the IaaS model, every demand of the increase is matched by increasing available resource, and this resource can be released.

Secondly, PaaS. When a company builds the CRM system, it clouds the middleware, the operating system and the testbed. PaaS offers the ability to directly add services to platforms. Most of the PaaS models provide a key service set, and the key service set can be upgraded to offer a wider range of services. For example, when a company is establishing its CRM, it chooses the PaaS service offered by Force.com. Force.com is a PaaS platform developed by Salesforce, and it uses its well-developed functions to help companies and the third party providers to deliver reliable online applications. Users can develop some extra services as individualized functions to expand the key service set, or companies can build internal PaaS platforms for internal uses.

Thirdly, use software as a service-use the CRM software completely. When companies establish CRM systems, they can select a SaaS provider to offer CRM services, but do not need to purchase software, hardware and middleware themselves. Building an internal CRM system, companies need to execute with a consultant. Using the CRM based on SaaS means that companies receive practical functions from the user end, and these functions should be coordinated and convenient for practices. Cloud users get access to software via cloud client ends (usually web browsers). Cloud users are allowed to conduct limited application settings, but cannot manage the infrastructure and platforms of applications’ operating systems. From the view of SaaS providers, they can either offer their CRM systems to their users respectively, or let all users to use only one system. The former way costs more than the latter way because of its complexity and license.

If the establishment of companies' CRM chooses to use SaaS model, the main characteristics are as follows:

1) CRM offers self-service according to clients' needs. Companies can obtain self-service computing resources such as the time and Internet storage of the server without interactions with service providers.

2) CRM can be visited by the Internet, so different user ends can visit the Internet via standard applications.

3) According to companies' CRM, the independent resource pool can be divided. Physical and virtual resources can be released dynamically according to companies' CRM needs, and the pooling provider computing resource offer services to multi tenants. Users usually do not control or know about the precise division of the resource pool, but they know that the resource pool is at the administrative area or at the center of data, such as a place possesses storage, calculation, internal storage, network bandwidth and virtual machines.

4) The rapid elasticity to deal with the use peak of CRM is a flexibility that can offer and release resources. For companies, the ability provided is unlimited (a large scale of computer resource as needed), and it can be purchased in any quantitative method at any time.

5) CRM service is measurable. The cloud system automatically control and better the resource usage by measures about different service types (such as storage, management, bandwidth, and the number of activated users). The usage of resource can be monitored, controlled, and can provide transparent reports for users (the model of pay as you use). Cloud software can use the advantage of cloud calculation to offer services, focusing on stateless, loose coupling, modularized and language explanation abilities.

Fourthly, BPaaS: installing the business process of CRM in the cloud. It is to say that when companies are organizing CRM business and establishing CRM systems, they standardize and collect the business process of customer relationship management, and they allocate it outside of companies. The most typical type in the customer relationship management area is BPaaS, which is to outsource customer services. Currently, many companies build shared service centers that provide uniform customer services for multi area, multi sections and multi companies. Meanwhile, shared service centers undertake parts of or the whole of the customer service process, such as complaints acceptance, queries explaining, and business follow-up. Such shared service centers can be allocated inside companies, and can also be outsourced to external institutes. The establishment of shared service centers must be standard-the business process and business interface should be standardized. Then, shared service centers should be collected in either physical way or logical way. Physical collection means that all customer service staffs work at the same physical location, considering the costs of human resource and rent, as well as the service level. Logical collection means that staff can work at different physical location, but they have to obey the same process of management and dispatch. Logical collection is more difficult to manage, and it needs a stronger support system. At last, the decision of outsourcing needs to be considered thoroughly in 
many aspects, such as costs, provider abilities, service level and the possibility of suitable management etc.

\section{Conclusions}

Leading CRM should get through the process of marketing, sales and service horizontally, and integrate all fields vertically. At the same time, the CRM should improve the organization frame and management mechanism constantly, as well as planting customer experience to the growth of the company. Modern CRM is mainly consisted with the following four parts:

Firstly is the customer oriented strategy, aiming to describe the customer-oriented value positions from the dimension of clients and companies. Companies need to clear their goals in three to five years, and also need to make plans to integrate recourses for their strategic goals. Moreover, companies need to resolve and quantify key success factors and the implementation route, in order to reach their goals.

Secondly is the consistent experience of cross channel interactions. A single channel cannot meet the need of a whole experience for users, so the integrated and highly consistent customer experience can increase sales and strengthen customer relationship. Companies need to define the functions of different channels and unite the contents of channel experience to offer consistent experience process.

Thirdly are the effective closed loop marketing, sales and services. Companies should connect customers to the main process of cash flow, simple the process organization, improve quick responses and quality, including getting through business process-from the market to clue, from the clue to cash return, and from troubles to solutions. They need to clear the organization responsibility that matches to the process, trans-department inspirational methods and KPI, and realize the automation of business process and collection of business data from end to end by using CRM package.

Fourthly is the effective integration of cross company operation. Companies should have a unified understanding of customers in all business area, and that sales and service information can be completely collected with supply chain plans and financial accountings. Specific functions include defining the dependent relationship between the supply chain, finance, development and closed loop process. Functional departments' characters and responsibilities should transfer data via IT system.

Companies' strategies constantly change according to changes of the competition environment. For Chinese companies, in the first period of economy transition, the changes of companies' strategies are concentrated on business strategies, mainly on the transferring from production-oriented to market-oriented. Meanwhile, products offered by companies are changing from one type to multi-types, and the characteristics of products emphasized by companies changed from only quantity to quality, function and costs etc. One of the specific behaviors of strategy changes is that market orientation becomes an important trait of companies' strategy. Marketing function was built rapidly and gradually occupied the hosting position. Currently, the production system's traits have radical changes because of the production management system imports, such as agile manufacturing, overall quality management, and computer integrated manufacturing system. The trait of this generation is that technology accumulation is more important, the combination of technology and innovation is more attended, flexibility and reaction speed are emphasized, and the diversity of products and their quality are more focused on, so companies must have the capability to respond to diversified customer needs Companies expect to find opportunities of realizing marketing and business values as well as changing business mode via the application of digitization technologies. However, every company's digitization needs to be built in its own way. The integrated advantages are not permanent. Even if the mother company improves its ability to create values, the relative advantages might be reduced. Therefore, the company's strategy must focus on the ongoing changes and trends because the opportunities of improvements can be reduced and eliminated. When exploiting company's strategies based on the integrated advantages, a company should stand on a dynamic point. It is very important for companies to take the trend and the future situations into consideration. From the balance of the value and complexity of digitization application, a company's digitization goes through following steps: 1 ) improving its operating efficiency, and better operating its business with the help of digitization technologies; 2) increasing its income, and promoting the business mode by using digitization technologies. By offering differentiated customer experiences, companies can expect business growth. Meanwhile, companies need to innovate business modes with the help of digitization technologies to transform business models, conduct industry subversion, and create business values. 


\section{Acknowledgements}

This research is supported by BLCU (Beijing Language and Culture University) Business School supported project (supported by the Fundamental Research Funds for the Central Universities) (Approval Number: 16YJ04002); Humanity and Social Science foundation of Ministry of Education of China (Project No. 15YJC630123).

\section{References}

[1] Levary, R.R. (2000) Better Supply Chains through Information Technology. Industrial Management, 42, 24-30.

[2] Barney, J. (1991) Firm Resources and Sustained Competitive Advantage. Journal of Management, 17, 99-120. http://dx.doi.org/10.1177/014920639101700108

[3] Cronin, M.J. (1997) Using the Web to Push Key Data to Decision Makers. Fortune, 136, 254.

[4] Loveman, G.W. (1994) An Assessment of the Productivity Impact on Information Technologies. In: Allen, T.J. and Morton, M.S., Eds., Information Technology and the Corporation of the 1990s: Research Studies, MIT Press, Cambridge, MA.

[5] Copacino, W.C. and Dik, R.W. (2001) Why B2B E-Markets Are Here to Stay. Accenture Outlook, No. 2, $22-29$.

[6] Chopra, S. and Meindl, P. (2004) Supply Chain Management: Strategy, Planning, and Operation. Second Edition, Person and Prentice Hall, New Jersey.

[7] Elliot, R., Martin, E.D. and Philip, T.E. (2003) Assessing the Effects of Operational Processes and Information Systems on Inventory Performance. Journal of Operations Management, 21, 63-80. http://dx.doi.org/10.1016/S0272-6963(02)00041-4

[8] Venkatraman, N. (1994) IT-Enabled Business Transformation: From Automation to Business Scope Redefinition. Sloan Management Review, 35, 73-87.

[9] Davenport, T.H. and Short, J.E. (1990) The New Industrial Engineering: Information Technology and Business Process Redesign. Sloan Management Review, 31, 11-27.

[10] Auramo, J., Kauremaa, J. and Tanskanen, K. (2005) Benefits of IT in Supply Chain Management: An Explorative Study of Progressive Companies. International Journal of Physical Distribution \& Logistics Management, 35, 82-88. http://dx.doi.org/10.1108/09600030510590282

\section{Submit or recommend next manuscript to SCIRP and we will provide best service for you:}

Accepting pre-submission inquiries through Email, Facebook, LinkedIn, Twitter, etc.

A wide selection of journals (inclusive of 9 subjects, more than 200 journals)

Providing 24-hour high-quality service

User-friendly online submission system

Fair and swift peer-review system

Efficient typesetting and proofreading procedure

Display of the result of downloads and visits, as well as the number of cited articles

Maximum dissemination of your research work

Submit your manuscript at: http://papersubmission.scirp.org/ 